\title{
ANÁLISIS SINÓPTICO SOBRE PROCESOS DE SECURITIZACIÓN EN CHILE Y EN LOS ESTADOS UNIDOS DE AMÉRICA
}

\author{
Eduardo Jequier Lehuedé \\ Profesor de Derecho Económico \\ Universidad Católica del Norte (Sede Coquimbo)
}

\section{INTRODUCCIÓN}

La securitización de activos, en cuanto herramienta alternativa de financiamiento derivada del creciente proceso de desintermediación que se observa en los mercados de valores a nivel global, constituye una de las grandes innovaciones financieras introducidas en los últimos años en nuestro ordenamiento. Si bien en Chile el proceso de securitización es de data reciente (ley $N^{\circ} 19.301$ ), sus primeras manifestaciones o antecedentes se remontan a la crisis que afectó a los Estados Unidos de Norteamérica en los años 30 , desarrollándose con mayor propiedad a raíz del perfeccionamiento que experimentó el mercado financiero hipotecario de ese país en la década de los setenta. No es el propósito de este trabajo el realizar un estudio acabado del origen y evolución de este instituto, ni los beneficios y/o imperfecciones de connotación económica que pueda presentar; sobre ello, pues, existen ya estudios muy completos y de destacado rigor científico '. Sin embargo, y considerando el innegable influjo que la securitización ha de reconocer en el país del norte, hemos estimado de interés el realizar, en forma sintética, un análisis comparativo de los aspectos jurídicos más relevantes de los procesos de securitización contenidos en el Título XVIII de la Ley №18.045, sobre Mercado de Valores, y aquellos surgidos y desarrollados en aquel país.

\section{1.- Activos Securitizables.}

1.1.- Con fecha 19 de marzo de 1994 se publicó en el Diario Oficial la Ley №19.301, que agregó el Título XVIII de la Ley de Mercado de Valores. En el proyecto de ley original, enviado por el ejecutivo, se contemplaban como securitizables los mutuos hipotecarios endosables, autorizados por ley (artículo 135). Agregaba el precitado proyecto que un Reglamento determinaría otros "títulos de crédito"

'Sobre el particular, KNAAK DONOSO, Marianne: Factoring, Securitización, ADR'S. Análisis, Regulación y Aplicación. Editorial Jurídica Conosur Ltda., $1^{2}$ Edición. Santiago, 1998. 
susceptibles de ser adquiridos por las empresas securitizadoras. En todo caso, los activos serán transferibles y deberán constar por escrito.

La Comisión de Hacienda de la Cámara de Diputados (en primer trámite constitucional) precisó el tipo de activos que podrían adquirir las antedichas empresas, y definió además las facultades que tendría la Superintendencia de Valores y Seguros en adelante la SVS- para autorizar otros títulos securitizables. Para ello, y por vía de indicación (Sesión $5^{a}$, en martes 08 de junio de 1993), se incluyeron como securitizables a los mutuos hipotecarios endosables autorizados por el D.L. №3.500, de 1980, y por los D.F.L. №251 y №252, de 1931 y 1960 , respectivamente (se trata de mutuos hipotecarios endosables para el financiamiento de la vivienda emitidos por bancos, agencias mutuarias y sociedades inmobiliarias autorizadas). Se facultó además a la SVS para determinar, mediante norma de carácter general, otros activos susceptibles de ser adquiridos por empresas de securitización. La indicación fue aceptada y pasó a formar parte del proyecto de la Comisión.

El proyecto aprobado por la Cámara de Diputados fue complementado por el Senado (en segundo trá mite constitucional), el que agregó las letras hipotecarias como activo securitizable.

1.2.- Con fecha 26 de agosto de 1999, se publicó en el Diario Oficial la Ley №19.623, sobre Securitización y Depósito de Valores, la que amplió significativamente el tipo de activos susceptibles de securitización. En el mensaje del ejecutivo, con que se inició el proyecto de modificación, se señala que con ella se busca transformar a la securitización en un mecanismo eficiente para el financiamiento de las concesiones de obras de infraestructura de uso público, para cuyo efecto se hacía necesario ampliar los activos ya referidos a aquellas obligaciones y derechos sobre flujos de pago emanados, por ejemplo, de las concesiones que regula la Ley №19.171.

El artículo 1, №2, letra a) de la referida Ley, substituyó entonces el inciso $1^{\circ}$ del artículo 135 de la Ley de Mercado de Valores, en términos tales de incluir los siguientes activos securitizables:

- Letras hipotecarias y mutuos hipotecarios autorizados por el D.F.L. №3, de 1997 (actual Ley de Bancos);

- Mutuos hipotecarios endosables autorizados por el D.L. NN3.500, de 1980, y por el D.F.L. №251 de 1931;

- Bienes y contratos de arrendamiento con promesa de compraventa de que trata el artículo 17 de la Ley №19.281; 
- Créditos y derechos sobre flujos de pago emanados de obra pública, de obra de infraestructura de uso público, de bienes nacionales de uso público o de las concesiones de estos bienes u obras; y

- Otros cré ditos o derechos que consten por escrito y que tengan el carácter de transferibles, con lo que el universo de activos securitizables se amplía considerablemente.

1.3.- Por su parte, con fecha 02 de febrero de 1995 y en uso de la facultad que le confiere el artículo 135 de la Ley №18.045, la SVS dictó la Norma de Carácter General -NCG- NN57, por la cual determinó otros títulos de crédito susceptibles de ser adquiridos por sociedades securitizadoras; sin perjuicio de los créditos y derechos transferibles referidos más arriba. Dicha NCG ha sido objeto de tres modificaciones, incorporándose por cada una de ellas nuevos instrumentos de crédito susceptibles de ser adquiridos por las sociedades securitizadoras, para el cumplimiento de su objeto social ${ }^{2}$. En suma, los títulos securitizables incluidos por vía de NCG por la SVS, son los siguientes:

a) Mutuos hipotecarios endosables otorgados con recursos de los fondos de inversión inmobiliaria (NCG No57);

b) Mutuos hipotecarios otorgados por asociaciones de ahorro y préstamo, conforme a la Ley №16.807 (NCG №57);

c) Créditos Hipotecarios de la Asociación Nacional de Ahorro y Préstamo (ANAP), regidos por el D.F.L. №205 de 1960, y que cumplan con las demás condiciones establecidas por la SVS (NCG No76);

d)Mutuos de mediano y largo plazo con garantía hipotecaria o prendaria, que reúnan determinados requisitos también regulados por la SVS (NCG №76);

e) Depósitos a plazo emitidos por Bancos establecidos en Chile (NCG N²76);

f) Contratos de Leasing sobre bienes muebles e inmuebles no regidos por la Ley №19.281, que reúnan determinados requisitos (NCG №76); №78);

g) Títulos de renta fija emitidos por la Tesorería General de la República (NCG

\footnotetext{
${ }^{2}$ NCG N²76, de 21 de agosto de 1997; NCG N278, de 21 de enero de 1998; y NCG N²85, de 08 de julio de 1999.
} 
h) Pagarés originados por empresas de obras sanitarias que correspondan a aportes financieros reembolsables, regulados por el D.F.L. №70 de 1988, de Obras Públicas (NCG №78);

i) Determinados bonos de reconocimiento emitidos por el Instituto de Normalización Previsional, que reúnan las condiciones establecidas por la SVS (NCG №78);

j) Bonos destinados al mercado de los EE.UU. de Norteamérica, expresados y pagaderos en moneda extranjera, emitidos por empresas chilenas que no sean Bancos o instituciones financieras (NCG N85); y

k) Bonos destinados al mercado de los Estados Unidos de Norteamérica, expresados y pagaderos en moneda extranjera, emitidos por Bancos e instituciones financieras en virtud del artículo 69 de la Ley General de Bancos (NCG №85).

1.4.- Tratándose del proceso de securitización en los Estados Unidos de Norteamérica, el universo de activos susceptibles de ser incluidos en una operación de securitización es bastante más amplio que el descrito en los ordinales precedentes. Como lo señala el profesor Steven Schwarcz, en dicho país todos los activos financieros son securitizables, desde una simple cuenta de luz o de agua hasta los flujos de peajes de concesiones de obras de infraestructura pública. Dichos activos son las denominadas "cuentas por cobrar", las que a su turno pueden ser de corto plazo (normalmente a 30 días), como ocurre con los créditos de las casas comerciales por concepto de la venta de sus productos o servicios; o pueden ser a largo plazo, como el pago de préstamos, arrendamientos, etc. Asimismo, y en la medida de que pueda predecirse razonablemente el porcentaje de incobrabilidad de estas cuentas, el "originador" (compañía dueña de las mismas) puede incluso incluir créditos que representan riegos de no poder cobrarse, como parte de un grupo estadísticamente grande de cuentas por cobrar.

Por último, en la actualidad las técnicas de securitización están siendo aplicadas incluso a activos que no constituyen por sí mismos derechos de pago, pero que pueden llegar a serlo en el tiempo.

\section{2.- Vehículos legales utilizados para securitizar.}

2.1.- En Chile, el proceso de securitización se verifica de la siguiente forma: Una sociedad anónima -en adelante la securitizadora- se constituye con el preciso y único

\footnotetext{
"SCHWARCS Steven L.: "The Alchemy of Asset Securitization". Stanford Journal of Law, Business \& Finances. Volumen I, N²1, 1994
} 
objeto de adquirir los activos referidos en el acá pite precedente para emitir, en base a ellos y con su respaldo, títulos de deuda -bonos- que serán colocados por la misma en el mercado de valores. Cada emisión de títulos de deuda de la securitizadora conforma, de pleno derecho, un patrimonio separado e independiente del patrimonio común de aquella.

La Ley №19.623 vino a flexibilizar las formalidades del proceso de securitización, por cuanto primitivamente era menester adquirir en forma previa los activos securitizables que integrarían el patrimonio separado -amén de enterar los activos colaterales exigidos por las clasificadoras de riesgo-, para luego emitir los respectivos títulos de deuda que se transarían en el mercado. Ello, pues, implicaba que la securitizadora debía contar de antemano con el total del capital necesario para la operación financiera, con los consiguientes costos y riesgos inherentes (tasas de interés y sus fluctuaciones). Con esta reforma se modifica el orden en que las cosas se hacen, por cuanto ahora el emisor puede prometer comprar los activos respectivos (prometiendo que esos activos tendrán una determinada clasificación de riesgo) para luego emitir y clasificar los títulos de deuda -que se inscriben en el registro pertinente de la SVS-, sin necesidad de requerir del capital íntegro ya referido.

Por su parte, este mecanismo no importa tampoco un riesgo para los inversores o adquirentes, ya que respecto de ellos la ley consulta la figura del "representante de los tenedores de bonos", que deberá percibir directamente el precio de tales títulos de deuda si la empresa securitizadora no ha cumplido con su obligación de enterar -en el patrimonio separado- la totalidad de los bienes, contratos, créditos y derechos que se individualizaron en el respectivo contrato de emisión de títulos de deuda con formación de patrimonio separado (art. 137, sustituido por el art. 1Nํㄴ de la Ley №19.623). La misma Ley recién citada se encarga de precisar el destino que el "representante de los tenedores de bonos" debe dar a los dineros recibidos (nuevo artículo 137 bis), y que consistirá basicamente en el pago del precio de los activos o de las deudas asociadas a ellos, o en la constitución de los activos colaterales comprometidos para mejorar la clasificación de riesgo de la emisión.

2.2.- Tratándose del sistema norteamericano, la situación es similar. Una vez que el "originador" (dueño de las cuentas por cobrar) identifica los activos que serán usados en la operación, los transfiere a una sociedad independiente, creada para ese solo fin, denominada "vehículo para un propósito especial o VPE". Dicha entidad emite títulos de deuda y los coloca -previa clasificación de riesgo- en el mercado de capitales (obteniendo así los recursos necesarios para adquirir los activos del originador), los que son pagados con el flujo de las mismas cuentas por cobrar. Sin embargo, este sistema consulta estructuras diversas: 
a) Estructura de Securitización "One-Off", en donde el "VPE" es creado por un originador específico y para una transacción también determinada, lo que implica muchas veces altos costos de transacción (sea que se trate de colocaciones privadas o de títulos ofrecidos públicamente por un VPE);

b) Canales de Securitización "con Múltiples Vendedores", en donde los originadores utilizan un VPE común (normalmente administrados por bancos comerciales o de inversión). Este mecanismo permite aprovechar las ventajas de economías de escala, pues permite a los originadores múltiples vender sus cuentas por cobrar a un VPE pre-existente;

c) En aquellos casos en que el originador no tiene "grado de inversión" (por la baja clasificación de riesgo de sus cuentas por cobrar), y con el fin de proteger a los inversores de los riesgos de la potencial quiebra de aquel, se recurre también a la securitización con dos VPE, en una estructura de dos niveles denominada "FINCO" (compañía de financiamiento). El originador vende las cuentas por cobrar a un VPE de su propiedad, mediante una "venta verdadera", el que luego vende esas mismas cuentas a un VPE independiente (mediante una venta para efectos contables), que es quien emite los títulos de deuda. Una vez que éste último paga los títulos emitidos, puede retransferir al VPE del originador los pagos y cuentas sobrantes (recibidos como sobregarantía), las que son recuperadas por el originador mediante la fusión con el VPE recién citado, o por vía de los dividendos que le reparte el mismo;

d) Para obtener una tasa de interés promedio menor para el originador, existe también la estructura de "títulos superiores/subordinados" a nivel de VPE. Los inversionistas sofisticados está dispuestos a adquirir títulos subordinados, recibiendo a cambio tasas de interés más altas (acordes con el mayor riesgo que asumen); pero esa mayor tasa se compensa con la tasa más baja que el originador debe pagar por los títulos no subordinados (o senior), lo que a fin de cuentas le significa un ahorro en comparación con el interés que habría pagado si se hubiera emitido sólo una clase de títulos.

\section{3.- Concepto de "true sale" o venta verdadera.}

Este concepto persigue, ante todo, separar los activos que adquiere la empresa securitizadora de toda contingencia o riesgo proveniente de una eventual quiebra del originador.

En Chile, y según se verá más adelante, lo anterior se obtiene por la vía de la formación de un patrimonio separado para cada emisión de bonos, independiente del patrimonio de la empresa securitizadora que los adquiere. El activo de dicho patrimonio estará constituido, de pleno derecho, por los bienes, contratos, créditos y derechos 
individualizados en el contrato de emisión y formación de patrimonio separado; y se tendrá como enterado sólo cuando el "representante de los tenedores de títulos de deuda" emita el certificado a que se refiere el actual artículo 137 de la Ley №18.045 (dando cuenta del aporte íntegro de dichos activos, y de encontrarse éstos libres de gravámenes, prohibiciones o embargos).

En consecuencia, debe tratarse de una venta que transforme al patrimonio respectivo en uno "inmune" a las acciones de los acreedores generales de la sociedad securitizadora, y remoto a los efectos de una eventual quiebra de la entidad originadora de esos activos. En todo caso, la Ley №18.045 sólo se pone en el caso de la quiebra de la sociedad securitizadora, más no del originador. Por ello, y considerando que la Ley №19.623 suprimió incluso la limitación que imponía el artículo 136 (los activos de cada patrimonio separado podian provenir de un mismo Banco o sociedad financiera sólo hasta un $50 \%$ del total), se hace necesario recoger el concepto de "true sale" del derecho norteamericano (estipulándolo en los respectivos contratos de emisión de títulos de deuda), que busca desligar jurídica y económicamente a los activos securitizados de los riesgos de su originador por la vía de pagar al mismo el valor de intercambio razonable que tengan las cuentas por cobrar. Dicho en otros términos, la eventual quiebra del originador no podrá afectar al VPE (en Chile a la empresa securitizadora), en la medida que el activo "cuentas por cobrar" sea reemplazado por su precio equivalente, pagado efectivamente.

Por último, es precisamente una "venta verdadera" lo que se persigue con la estructura de "títulos superiores/subordinados", referida en el párrafo anterior, pues con ella el originador limita su derecho a reclamar cualquier valor residual de las cuentas por cobrar vendidas al VPE independiente (que emite los títulos de deuda), por intermedio del VPE de propiedad del originador.

4.- Cesión de derechos y eventuales notificación y/o aceptación del deudor cedido. Defensas del deudor cedido.

El primitivo artículo 135 de la Ley №18.045, introducido por la Ley №19.301, nada decía respecto de la forma de hacer oponibles los efectos de un contrato de emisión de títulos de deuda con formación de patrimonio separado, a los deudores cedidos. Por ello, y ante el silencio de la ley especial en este aspecto, cobraban plena aplicación, en mi concepto, las normas contenidas en los artículos 1901 y siguientes del Código Civil.

La anterior omisión fue expresamente abordada por la Ley №19.623, al introducir al artículo 135 de la Ley de Mercado de Valores -a iniciativa del Senado- sus nuevos incisos $3^{\circ}, 4^{\circ}$ y $5^{\circ}$. Según éstos, la transferencia de activos a la empresa securitizadora le será oponible a los deudores cedidos desde la fecha de otorgamiento 
del contrato de emisión con formación de patrimonio separado o de sus escrituras complementarias. De consiguiente, no será necesario notificar dicha transferencia al deudor cedido, en los términos de la normativa común ya citada. Tampoco será necesario obtener la autorización o consentimiento del deudor.

Del mismo modo, los respectivos deudores sólo podrán oponer al cesionario (sociedad securitizadora) aquellas excepciones personales que tengan en su contra; cualquiera otra excepción le será inoponible al antedicho cesionario adquirente. Así lo señala expresamente el artículo 135 inciso $3^{\circ}$ actual.

\section{5.- Conformación de "segregated accounts" o patrimonio separado.}

5.1.- Una de las principales características del proceso de securitización en Chile es que, según la Ley, al otorgarse el respectivo contrato de emisión con formación de patrimonio separado, se forma de inmediato y de pleno derecho un patrimonio distinto e independiente del patrimonio común de la sociedad securitizadora. El pasivo de dicho patrimonio estará compuesto por las obligaciones de que dan cuenta los títulos de deuda emitidos; y su activo por los bienes, contratos, créditos y demás derechos adquiridos o prometidos adquirir en el respectivo contrato. En otros términos, la sociedad securitizadora tendrá un patrimonio propio, pero a la vez irá creando patrimonios separados mediante la compra de cada paquete de activos securitizables. Lo anterior permite independizar la suerte de estos patrimonios respecto del patrimonio común, evitándose así que los acreedores de la sociedad accionen sobre los mismos. Más aun, el artículo 137 de la Ley №18.045 señala expresamente que la sociedad securitizadora no podrá gravar, enajenar ni prometer vender o enajenar los activos del respectivo patrimonio separado, a menos que el representante de los tenedores de títulos de deuda consienta en ello. Del mismo modo, el artículo 138 señala que los acreedores de la sociedad no podrán en caso alguno hacer efectivos sus créditos sobre los bienes que conformen el activo del patrimonio separado, ni podrán afectar tales activos con embargos, medidas precautorias, gravámenes o hipotecas.

En síntesis, el riesgo de la emisión o del patrimonio separado deberá provenir sólo de la calidad o características de los activos securitizados y de los colaterales que deben enterarse, más no del riesgo propio de la securitizadora.

5.2.- En el sistema norteamericano, el concepto de patrimonio separado se traduce en la realización de una "venta verdadera", que sea eficaz -según la ley de quiebras- para separar las cuentas por cobrar de aquellos bienes que serían afectados por una eventual declaración de quiebra del originador. Según se dijo más arriba, este fin se obtiene también por la vía de limitar el derecho del originador sobre el valor residual de las cuentas por cobrar vendidas al VPE (securitización con dos VPE en una estructura de dos niveles o "FINCO"), evitando así el riesgo de quiebra de aquél. 


\section{6.-"Credit Enhancement" y "Liquidity Facilities".}

6.1.- En el sistema norteamericano, tanto los mecanismos de securitización "one-off" como los de vendedores múltiples, pueden ser favorecidos con los denominados "instrumentos de mejora del crédito" o "credit enhancement". Según esto, el repago de los títulos de deuda emitidos se garantiza -en todo o parte- por entidades de reconocido prestigio en el negocio de evaluar dichos riesgos, ya sean bancos (que otorgan cartas de crédito) o compañías aseguradoras (emitiendo pólizas de seguro). Lo que se busca con este mecanismo es mejorar la clasificación de riesgo de la emisión, lo que conlleva una tasa de interés más baja.

Sin embargo, en las estructuras de "múltiples vendedores" se utiliza también el sistema de las "fuentes de liquidez" o "liquidity facilities", que consiste en que terceros dignos de crédito garantizan ya no el cumplimiento por parte de los deudores respectivos, sino el pago puntual de las cuentas por cobrar vendidas al VPE. Este mecanismo, proporcionado normalmente por los bancos, asegura que el mecanismo de vendedores múltiples tendrá la liquidez necesaria para cumplir con el pago de sus emisiones de corto plazo.

6.2.- En Chile, el sistema de securitización consulta también la posibilidad de que las compañías privadas de clasificación de riesgo exijan aportes adicionales a la sociedad securitizadora, los que serán pactados en el respectivo contrato de emisión de títulos de deuda con formación de patrimonio separado (artículo 137 inciso $5^{\circ}$ ). En dicho contrato, el emisor se obliga a enterar los activos colaterales que sean necesarios para obtener la clasificación de riesgo comprometida.

\section{7.- Quiebra.}

7.1.- Conforme lo señala el artículo 146 de la Ley №18.045, la quiebra de la sociedad securitizadora sólo afectará a su patrimonio común, sin originar la quiebra de los patrimonios separados. Agrega dicha disposición que un patrimonio separado nunca podrá ser declarado en quiebra, sino que sólo entrará en liquidación cuando concurra a su respecto alguna de las causales que habrían originado su quiebra. La administración y liquidación estará a cargo del representante de los tenedores de títulos de deuda, o de quien designe la junta de tenedores de tales títulos.

7.2. - En el sistema norteamericano, el concepto de venta verdadera o "true sale" ya visto implica que el VPE no será afectado por la quiebra del originador. Para ello, el VPE ve limitadas en forma estricta las actividades que le son permitidas, de manera de evitar que acreedores del originador puedan accionar en su contra. Además, el VPE debe mantener su independencia frente al originador, guardando ante éste las 
formalidades propias de un tercero; más aun, deberá mantener siempre a uno o más directores independientes del originador, cuando éste lo controle. 